\title{
"Meaningfulness" in tachistoscopic thresholds, serial learning, and association measurement
}

\author{
Wilma A. Winniek and Melvyn Ellner \\ QUEENS COLLEGE OF THE CITY UNIVERSITY OF NEW YORK
}

\begin{abstract}
Abstraet
"Meaningfulness" was induced by pairing nonsense syllables with pictures of common objects, and its effect was studied in three situations. Tachistoscopic thresholds were found to be identical for such syllables and for syllables previously exposed without pictures (frequency syllables). When serial learning was measured in lists composed of the two kinds of syllables, again no difference was found. In a third comparison, no difference was found in the mean numbers of associations for the meaning syllables and for syllables not seen before. Results are discussed in the light of studies by Riley \& Phillips (1959) and by Taylor (1958). Introduetion
\end{abstract}

Taylor (1958) has demonstrated that meaningfulness of nonsense syllables, though an important variable in serial learning, is apparently not relevant to tachistoscopic threshold measurement. This contrast was shown in an experiment concerned only with the measurement of tachistoscopic thresholds. Two measures of meaningfulness were used: one was the associative value of nonsense syllables; the other, the concern of the present study, was experimentally induced by pairing nonsense syllables with pictures of common objects. Nonsense syllables paired in this manner showed duration thresholds not different from those for nonsense syllables exposed equal numbers of times but without pictures.

The present study raises two questions: (1) Would "meaning" induced in the manner described affect serial learning, as seems implied by Taylor (1958)? (2) Would this "meaning" be revealed as an effect upon a common measure, the associative value of nonsense syllables? Riley \& Phillips (1959) showed that mere familiarization with syllables exerted no effect upon associative value; would there be an effect from pairing syllables with pictures of meaningful objects?

Two experiments are reported. The first experiment, partially replicating Taylor's (1958) procedure, exposed nonsense syllables both by themselves (frequency) and paired with pictures of common objects (meaning) to Ss; following this, tachistoscopic thresholds in one group and speed of serial learning in a second group were determined for the frequency and the meaningful syllables. In the second experiment, syllables were exposed paired with pictures of common objects; following exposure, the associative values of these syllables and of syllables not seen before were determined. Method

Experiment I: Recognition Thresholds and Serial Learning. Two separate groups of Ss were used: 20 introductory psychology students served as Ss for threshold measurement, and 20 for serial learning. Five additional Ss were dismissed because of incomplete learning of the meaningful associations.

Identical materials were used in the two tasks, consisting of 20 nonsense syllables of $50 \%$ associative value (Glaze, 1928) randomly assigned to either the frequency or the meaningful condition, duplicating Taylor's (1958) experimental arrangement. Training trials followed her experimental procedure, except that all Ss saw both frequency and meaningful syllables in random arrangement.

Tachistoscopic recognition thresholds were measured by a Gerbrands mirror tachistoscope; the nonsense syllables were typed on the cards in capital letters. After practice at recognizing English words in the tachistoscope, Ss were randomly presented the meaning and the frequency syllables at a starting exposure of .01 sec. and at increased durations until correctly recognized.

Of the Ss who participated in the measurement of serial learning, half learned the list of meaningful syllables first, followed after a 5-min. rest by the lists of frequency syllables; the other half reversed the order. Both kinds of lists were arranged in accord with standard principles of serial list construction (Hilgard, 1951). The method of anticipation was used, and learning continued to a criterion of one errorless trial.

Experiment II: Measurement of Associative Value. This experiment was carried out as a group experiment, using two classes in beginning experimental psychology; there were 19 and 16 Ss in the two groups.

Training trials were represented to the groups as part of an experiment on language learning. An opaque projector exposed five syllables printed with $1 / 2$ in. Letraset letters beneath five of the pictures of common objects used in Experiment I. These syllables, different in the two groups, were exposed at a 2-sec. duration for five trials, with $\mathrm{E}$ pronouncing the syllables aloud as they were shown. Control and meaning syllables were interchanged in the two groups.

Approximately $2 \mathrm{~min}$. after completion of training, the measurement of association values of these syllables and of five control syllables was made. Ss were given booklets, with the first sheet containing a list of the meaning and control syllables (not seen before), followed by pages with one syllable on each page, in random sequence. The Ss task was to identify on the first page those syllables that had been paired with pictures by 
Table 1

Means (and SDs) for threshold measurement and serial learning of frequency and meaningful syllables.

$\begin{array}{ccc} & \begin{array}{c}\text { Frequency } \\ \text { Syllables }\end{array} & \begin{array}{c}\text { Meaningful } \\ \text { Syllables }\end{array} \\ \text { Threshold } & 2.53 & 2.50 \\ \text { (in } 1 / 100 \text { sec.) } & (1.17) & (1.05) \\ \text { Serial Learning } & 16.75 & 15.85 \\ \text { (trials to criterion) } & (5.42) & 5.85\end{array}$

writing on this page the names of the objects next to the syllables. (All Ss did this accurately.) Following this preliminary test, Ss were instructed that at the first tone sounded by the tape recorder they were to turn the page and write next to the syllable on that page all the words that they associated with that syllable. Instructions specified that only associations suggested by the syllable, not chains of associations, were to be given (Noble, 1952). Tones were sounded at 30-sec. intervals to accord with the usual operational definition of associative value (Noble, 1952).

\section{Results}

Table 1 summarizes the data obtained in Experiment I. From these results, it is apparent that neither threshold measurement nor serial learning has been affected by this form of induced "meaning"; the mean thresholds for frequency syllables (2.53 hundredths sec.) and for meaningful syllables (2.50 hundredths sec.) were close enough to preclude statistical analysis, as were the data for serial learning for frequency (16.75 trials) and for meaningful (19.85 trials) syllables.

The mean numbers of associations for the meaning and for the control syllables in the two groups are shown in Table 2. Again these four sets of data are close to identity, indicating no effect either of the meaning variables or of the particular set of syllables used.

\section{Diseussion}

The data reported in this study do not question the basic conclusion from Taylor's (1958) study-namely that the meaningfulness variable may affect serial learning and yet exert no parallel effect upon recognition thresholds. Such a conclusion is borne out by Taylor's (1958) finding that normative association values, though known from previous studies to affect serial learning, had no influence on recognition thresholds. A similar contrast was reported in a recent study by Gibson et
Table 2

Mean numbers of associations (and SDs) to meaningful and control nonsense syllables in the two groups.

$\begin{array}{ccc} & \begin{array}{c}\text { Meaningful } \\ \text { Syllables }\end{array} & \begin{array}{c}\text { Control } \\ \text { Syllables }\end{array} \\ \text { Group I } & 3.83 & 3.77 \\ & (1.23) & (1.03) \\ \text { Group II } & 4.18 & 4.13 \\ & (1.24) & \mathbf{( 1 . 7 3 )}\end{array}$

al (1964), who found meaningful nonsense syllables to be more easily retained than pronounceable syllables, while pronounceable syllables were the more easily recognized. In similar vein, Winnick \& Kressel (1965) found concrete words to be learned more easily than abstract, while no such difference was found in the tachistoscopic thresholds for these two kinds of words.

The data reported do question Taylor's (1958) assumption that the procedure of pairing nonsense syllables with pictures of objects suffices to induce meaning. Neither the data on serial learning nor the direct measurement of association value provides any basis for this assumption. The results of the present experiment, combined with Riley \& Phillips' (1959) finding that familiarization training does not increase the association value of nonsense syllables, leave open for future experimentation the problem of determining the actual basis for the meaning of nonsense syllables. References

GLAZE, J. A. The association value of non-sense syllables. J. genet. Psychol., 1928, 35, 255-269.

GIBSON, E. J., BISHOP, C.H., SCHIFF, W., \& SMITH, J. Comparison of meaningfulness and pronunciability as grouping principles in the perception and retention of verbal material. J. exp. Psychol., 1964, 67, 173-182.

HILGARD, E. R. Methods and procedures in the study of learning. In Stevens, S. S. (Ed.), Handbook of experimental psychology. New York: Wiley, 1951. Pp. 517-567.

NOBLE, C. E. An analysis of meaning. Psychol. Rev., 1952, 59, 421-430.

RILEY, D..A., \& PHILLIPS, L.W. The effects of syllable familiarization on rote learning, association value, and reminiscence. J. exp. Psychol., 1959, 57, 372-379.

TAYLOR, J. S. Meaning, frequency and visual duration thresholds. J. exp. Psychol., 1958, 55, 329-334.

WINNICK, W. A., \& KRESSEL, K. Tachistoscopic thresholds, pairedassociate learning, and free recall as a function of abstractnessconcreteness and word frequency. J. exp. Psychol., 1965, in press. Note

1. Supported by a National Institute of Health grant ( $M H$ 10538-01). to the first author, entitled "Verbal learning and word recognition: some comparisons." 